\title{
Femoral vein homograft for neoaortic reconstruction in the Norwood stage 1 operation: A follow-up study
}

\author{
Thomas J. Seery, MD, ${ }^{a}$ Pranava Sinha, MD, ${ }^{b}$ David Zurakowski, $\mathrm{PhD},{ }^{\mathrm{c}}$ and Richard A. Jonas, $\mathrm{MD}^{\mathrm{b}}$
}

Objective: The aim of this study was to analyze our experience with the cryopreserved femoral vein homograft in comparison with standard biomaterials for neoaortic reconstruction in the Norwood stage 1 operation.

\begin{abstract}
Methods: All patients who underwent the Norwood operation from September 2004 to April 2011 were analyzed retrospectively $(n=107)$. Patients were grouped into group A (cryopreserved femoral vein homograft; $n=72$ ) or group $B$ (other; $n=35$ ). Intergroup comparisons and dimensional analyses of all available angiograms were performed. Two surgical techniques, "standard homograft cuff" and "homograft tube," were compared.
\end{abstract}

Results: Multivariable Cox regression analysis revealed use of biomaterial other than femoral vein $(P=.01$; hazard ratio, 3.0; 95\% confidence interval [CI], 1.4-6.4), weight less than $2.5 \mathrm{~kg}$ at the time of stage 1 $(P=.01$; hazard ratio, $3.7 ; 95 \% \mathrm{CI}, 1.7-7.8)$, and need for extracorporeal membrane oxygenator support after stage $1(P<.001$; hazard ratio, $13.8 ; 95 \% \mathrm{CI}, 5.9-31.9)$ as significant independent predictors of overall mortality. Improved late survival at 48 months was seen with the femoral vein homograft compared with other biomaterials when a "homograft tube with end-to-side ascending aortic reimplantation technique" was used (group A [75\%] vs group B [44\%]; $P=.03$ ). With the use of the "homograft cuff technique," survival was similar for femoral vein homografts and other biomaterials (group A [67\%] vs group B $[61 \%] ; P=.85$ ). Similar neoaortic coarctation rates were seen in both groups (A: $25 / 59[42 \%]$ vs B: $12 / 26[46 \%] ; P=.81$ ). A progressive increase in the diameter of the neoaorta was seen over time in both groups with both technical modifications (tube grafts prestage 2 vs pre-stage 3: group A [10.61 $\mathrm{mm} \pm 1.93 \mathrm{vs} 13.74 \mathrm{~mm} \pm 3.16][P<.001]$ and group B [13.93 $\mathrm{mm} \pm 6.71$ vs $17.38 \mathrm{~mm} \pm 5.92][P=.049])$; cuff repair pre-stage 2 to pre-stage 3: group A [13.98 $\mathrm{mm} \pm 2.13$ vs $19.09 \mathrm{~mm} \pm 4.18][P=.002]$ and group B [16.06 $\mathrm{mm} \pm 3.05$ vs $19.73 \mathrm{~mm} \pm 2.93]$ $[P<.001])$. The neoaortic Z-scores were generous with the use of homograft cuffs and modest when homograft tubes were used and maintained in range over the follow-up time.

Conclusions: Survivals are improved with the use of femoral vein homograft for neoaortic reconstruction for Norwood stage 1 operation, especially when used as a homograft tube with end-to-side aortic reimplantation. Femoral vein homografts have similar recoarctation rates compared with standard biomaterials. Progressive growth/dilation of the neoaorta in proportion to somatic growth is seen with femoral vein tube grafts. (J Thorac Cardiovasc Surg 2013;146:550-6)

Aortic or pulmonary homografts are the most commonly used supplemental biomaterials for neoaortic reconstruction in the stage 1 Norwood operation. The variable wall thickness of aortic homografts and the length limitation of the pulmonary homografts pose technical challenges for neoaortic reconstruction, especially in patients with a diminutive ascending aorta. Additionally, limited availability of pediatric aortic and pulmonary homografts and their high cost have led to development of alternative methods of

\footnotetext{
From the Departments of Cardiology ${ }^{\mathrm{a}}$ and Cardiovascular Surgery, ${ }^{\mathrm{b}}$ Children's National Medical Center, Washington, DC; and the Department of Anesthesia and Surgery, ${ }^{\mathrm{c}}$ Boston Children's Hospital, Harvard Medical School, Boston, Mass. Disclosures: Authors have nothing to disclose with regard to commercial support. Received for publication June 15, 2012; revisions received Oct 12, 2012; accepted for publication Dec 5, 2012; available ahead of print Jan 14, 2013.

Address for reprints: Richard A. Jonas, MD, Children's National Heart Institute, Cohen Funger Professor of Surgery, Children's National Medical Center, 111 Michigan Ave, NW, Washington, DC 20010 (E-mail: lyoung@cnmc.org). $0022-5223 / \$ 36.00$

Copyright (C) 2013 by The American Association for Thoracic Surgery http://dx.doi.org/10.1016/j.jtcvs.2012.12.010
}

neoaortic reconstruction for the Norwood stage 1 procedure. ${ }^{1-3} \mathrm{We}^{4}$ reported the use of cryopreserved femoral vein homograft as an alternative biomaterial for neoaortic reconstruction in the stage 1 Norwood operation in $2009 .{ }^{4}$ This report documents short- to intermediate-term follow-up.

\section{METHODS}

Owing to the retrospective nature of the study, the institutional review board at Children's National Medical Center approved waiver of documented consent. All patients who underwent the Norwood stage 1 operation for hypoplastic left heart syndrome (HLHS) or HLHS variants between September 2004 and April 2011 were included in the study. The patients were grouped according to the homograft material used for neoaortic reconstruction into group A (femoral vein homograft) and group B (material other than femoral vein homograft, ie, aortic or pulmonary homograft, autologous pericardium, and prosthetic material). Each group was further divided into 2 categories by type of repair; standard homograft cuff technique or circumferential tube homograft (with end-to-side ascending aortic anastomosis, or without end to side aortic reimplantation or the "double-barrel" technique). Demographic, preoperative, intraoperative, postoperative, and follow-up data were reviewed. 


\section{Abbreviations and Acronyms \\ CI = confidence interval \\ $\mathrm{ECMO}=$ extracorporeal membrane oxygenator \\ HLHS $=$ hypoplastic left heart syndrome}

\section{Operative Technique}

All patients underwent stage 1 Norwood reconstruction via a median sternotomy, hypothermic low-flow cardiopulmonary bypass, and circulatory arrest. A pH-stat strategy, goal hematocrit on bypass of more than $30 \%$, and deep hypothermic circulatory arrest for arch reconstruction were applied in all patients. The technical aspects of the surgical procedure are widely described elsewhere. ${ }^{5}$ It is our preference to use a right ventricle-pulmonary artery conduit as a source for pulmonary blood flow unless it is technically not feasible (left ventricular morphology of the single ventricle, inaccessible right ventricular infundibulum owing to cardiac position, or presence of large coronaries contraindicating a ventriculotomy), and then a systemic-pulmonary artery shunt is used. Neoaortic reconstruction was performed using either a homograft cuff or a circumferential homograft tube. Depending on the size of the ascending aorta, either end-to-side ascending aortic reimplantation was performed or a homograft tube was used without end-to-side ascending aortic reimplantation.

\section{Homograft Cuff Technique}

After division of the ductus arteriosus at its junction with the descending aorta, the resulting aortotomy is extended distally onto the descending aorta for several millimeters and proximally along the undersurface of the aortic arch, ascending to the level of the divided main pulmonary artery. An anastomosis is fashioned between the proximal portion of the divided main pulmonary artery and the filleted aorta with a supplementary cuff of homograft (Figure 1, A).

\section{Circumferential Tube Homograft Technique}

With end-to-side ascending aortic reimplantation. The ductus arteriosus is transected at its junction with the descending aorta. The ascending aorta is divided at its junction with the proximal arch. The resulting orifice in the proximal arch is extended across the undersurface of the aortic arch through the ductal orifice and beyond onto the descending aorta beyond the coarctation shelf. The homograft, beveled appropriately, is used as a circumferential tube to connect the divided proximal pulmonary artery to the undersurface of the arch and proximal ascending aorta. With the neoaorta filled with saline, to both deair and distend the homograft, an appropriate-sized opening is created along the right lateral aspect of the proximal homograft. The ascending aorta is spatulated and anastomosed end to side to the homograft tube with interrupted sutures at the heel and the remainder continuous 7-0 Prolene polypropylene (Ethicon, Inc, Somerville, NJ) (Figure 1, B). Creation of a long ascending aortic anastomosis limits the nongrowing rim to a few millimeters at the proximal and distal homograft tube anastomotic sites only, with the majority of the homograft circumference still having the growth potential.

Without end-to-side aortic reimplantation, "doublebarrel." The "double-barrel" technique is suitable for patients with an ascending aorta larger than $5 \mathrm{~mm}$. Often the arterial cannula is placed directly into the mid to distal ascending aorta along its right lateral aspect. After division of the ductus arteriosus, the resulting aortotomy is extended distally onto the descending aorta. Proximally, the aortotomy is extended along the undersurface of the aortic arch to the ascending aorta. It is important to extend the ascending aortotomy inferiorly beyond the aortic cannulation site to avoid narrowing of the ascending aorta at this level. The circumferential homograft tube is shaped appropriately and a beveled
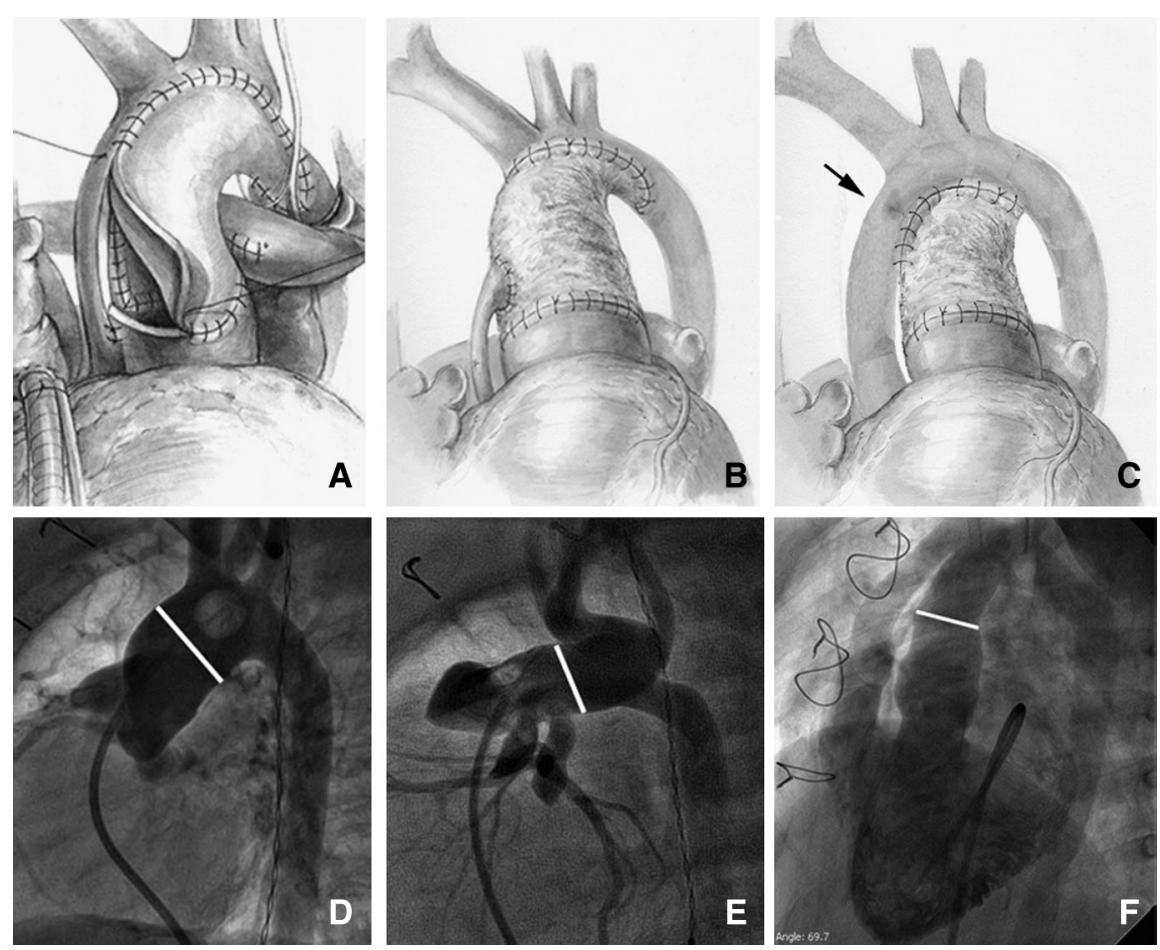

FIGURE 1. Technical modifications used for neoaortic reconstruction. A, Homograft cuff technique. B, Homograft tube with end-to-side ascending aortic reimplantation. C, Homograft tube without end-to-side aortic reimplantation, "double-barrel." Black arrow depicts site of aortic cannulation. Lateral aortograms for the 3 techniques. D, Homograft cuff. E, Homograft tube with end-to-side ascending aortic reimplantation. F, Homograft tube without end-to-side aortic reimplantation, "double-barrel." White line depicts sites of angiographic measurements for each of the techniques. 
anastomosis is fashioned to the aortotomy. The homograft tube is cut to length and anastomosed end to end to the proximal divided main pulmonary artery (Figure 1, C).

\section{Angiographic Data}

Neoaortic dimensions were estimated from all available angiograms from all cardiac catheterizations performed (pre-stage 2, pre-stage 3, and others). The lateral projection of the aortic arch angiogram was used to measure the diameter of the ascending neoaorta in millimeters (Figure 1, $A$ to $C$ ). To minimize interobserver variability, 2 independent observers made measurements and the average of the 2 was used for analysis. Dimensional comparisons were made between group A and group B, as well as between "homograft cuffs" and "homograft tubes." Ascending aortic Z-scores were calculated using standard published data. ${ }^{6}$

Neoaortic coarctation was defined by the need for intervention owing to narrowing of the reconstructed aorta (balloon angioplasty or surgical aortic arch augmentation) at any time during the study period. The criteria for reintervention at the time of cardiac catheterization were significant angiographic narrowing (coarctation index $<0.7^{7}$ ) or pressure gradient of more than $15 \mathrm{~mm} \mathrm{Hg}$ (mean) $)^{8}$ or more than $20 \mathrm{~mm} \mathrm{Hg}$ (peak). Surgical arch augmentation was considered for failed balloon angioplasty or aortic arch narrowing considered unsuitable for balloon angioplasty.

\section{Statistical Analysis}

All continuous data are presented as mean \pm standard deviation, and categorical data are presented as number (percentages). Patient survival was analyzed with the Kaplan-Meier method and groups were compared using the log-rank test. Cox multivariable regression analysis was used to determine independent risk factors of mortality with hazard ratios to allow for censoring and to adjust for covariates, including biomaterial, patient weight, and need for support with an extracorporeal membrane oxygenator (ECMO). Inasmuch as femoral vein homograft recipients (group A) were the more contemporary patients being compared with historical controls (group B), date of operation was included in the multivariable analysis, to account for the "era effect."

Ascending aorta diameter and Z-scores followed a normal Gaussianshaped distribution and therefore were compared between femoral vein homograft and other biomaterial groups using the Student $t$ test. Comparison of aortic diameter for each group between pre-stage 2 and pre-stage 3 were assessed using paired $t$ tests. Rate of neoaortic coarctation was compared using Fisher's exact test and logistic regression was applied to identify predictors of coarctation. The number of operative survivors constituted the denominator for dimensional and neoaortic coarctation analyses. Statistical analysis was performed using SAS version 9.2 (SAS Institute, Inc, Cary, NC).

\section{RESULTS}

Between September 2004 and April 2011, a total of 107 patients underwent the Norwood stage 1 procedure. Cryopreserved femoral vein homograft was used in 72 patients (group A), and in 35 patients biomaterials other than femoral vein were used for neoaortic reconstruction (group B) (31 aortic-pulmonary homograft, 3 autologous pericardium, 1 polytetrafluoroethylene [Gore-Tex; registered trademark of W. L. Gore \& Associates, Inc, Flagstaff, Ariz). In February 2007, we switched to exclusively using cryopreserved femoral vein homograft for neoaortic reconstruction in the Norwood stage 1 operation. All patients who underwent the procedure between February 2007 and April 2011 received the femoral vein homograft (group A), whereas before this period (September 2004 and February
2007) all patients underwent the procedure using other biomaterials (group B).

The standard homograft cuff technique was used in 15 patients in group A and 18 patients in group B. A total of 48 patients (32 group A, 16 group B) underwent neoaortic reconstruction using a circumferential homograft tube with end-to-side ascending aortic reimplantation. The majority of patients $(84 \%)$ in group A that underwent this technique had a diminutive ascending aorta $(<2 \mathrm{~mm})$. This was also true in group B $(81 \%)$. The presence of an adequate-sized ascending aorta allowed neoaortic reconstruction using a circumferential homograft tube without end-to-side aortic reimplantation in 26 patients in group A, whereas this was the technique used for only 1 of the patients in group B.

The anatomic, preoperative, intraoperative, and postoperative details of all patients are detailed in Tables 1 and 2 . To date, 78 patients have undergone stage 2 (bidirectional Glenn) and 45 stage 3 (Fontan) procedures.

\section{Mortality}

There were a total of $22(20.5 \%)$ operative deaths (13 in group A; 9 in group B), with nonsignificant differences between the 2 groups (group A, 18.1\%; group B, 25.7\%; $P=.45)$. Excluding the 4 nonhomograft patients from group B (3, autologous pericardium; 1, polytetrafluoroethylene) did not affect the mortality (group A, $18.1 \%$; group B, $25.8 \%$; $P=.43$ ). At a median follow-up of 3.4 years (1.6-5.2 years), there were 7 late deaths in group A and 7 in group B, amounting to an overall mortality of $27.8 \%$ in group $A$ and $45.7 \%$ in group B $(P=.08)$. There were a total of 4 interstage $1-2$ deaths (1, group A; 3, group B) and 6 interstage 2-3 deaths (5, group A; 1 , group B). Death after Fontan completion occurred in 4 patients (1, group A; 3, group B) (Table 1).

Multivariable Cox regression analysis revealed the use of biomaterial other than femoral vein $(P=.01$; hazard ratio, $3.0 ; 95 \%$ confidence interval $[\mathrm{CI}], 1.4-6.4)$, weight less than $2.5 \mathrm{~kg}$ at the time of stage $1(P=.01$; hazard ratio, 3.7; 95\% CI, 1.7-7.8), and need for ECMO support after stage $1(P<.001$, hazard ratio, 13.8; 95\% CI, 5.9-31.9) as significant independent predictors of overall mortality (Table 3). Improved late survival at 48 months was seen with the femoral vein homograft compared with other biomaterials when a "homograft tube with end-to-side ascending aortic implantation technique" was used (group A $[75 \%]$ vs group B $[44 \%] ; P=.03)$. With use of "homograft cuff technique," survival was similar for femoral vein homografts and other biomaterials (group A [67\%] vs group B $[61 \%] ; P=.85$ ) (Figure 2).

\section{Dimensional Analysis}

By the end of the study period, a total of 202 cardiac catheterizations had been performed in 71 survivors. These included 147 planned (92, pre-stage 2 and 55, pre-stage 3) 
TABLE 1. Comparison of anatomic, preoperative, intraoperative, postoperative, and neoaortic dimensions

\begin{tabular}{|c|c|c|c|c|}
\hline Variable & Overall $(n=107)$ & Group A $(n=72)$ & Group B $(\mathbf{n}=35)$ & $P$ value \\
\hline \multicolumn{5}{|l|}{ Anatomic } \\
\hline \multicolumn{5}{|l|}{ Sex } \\
\hline Male & $54(50 \%)$ & $34(47 \%)$ & $20(57 \%)$ & - \\
\hline Female & $53(50 \%)$ & $38(53 \%)$ & $15(43 \%)$ & - \\
\hline Prematurity ( $<36$ wk gestation) & $13(12 \%)$ & $9(13 \%)$ & $4(11 \%)$ & - \\
\hline Weight $<2.5 \mathrm{~kg}$ & $17(16 \%)$ & $11(15 \%)$ & $6(17 \%)$ & - \\
\hline HLHS & $71(66 \%)$ & $47(66 \%)$ & $24(69 \%)$ & - \\
\hline Aortic atresia/mitral atresia & $49(69 \%)$ & $32(68 \%)$ & $17(71 \%)$ & - \\
\hline Aortic stenosis/mitral stenosis & $13(18 \%)$ & $10(21 \%)$ & $3(13 \%)$ & - \\
\hline Aortic atresia/mitral stenosis & $9(13 \%)$ & $5(11 \%)$ & $4(16 \%)$ & - \\
\hline \multicolumn{5}{|l|}{ HLHS variants } \\
\hline DORV & $15(14 \%)$ & $9(13 \%)$ & $6(17 \%)$ & - \\
\hline Unbalanced AVC defect & $10(9 \%)$ & $8(11 \%)$ & $2(6 \%)$ & - \\
\hline Tricuspid atresia & $5(5 \%)$ & $2(3 \%)$ & $3(9 \%)$ & - \\
\hline DILV & $5(5 \%)$ & $4(6 \%)$ & $1(2 \%)$ & - \\
\hline D-TGA & $1(1 \%)$ & $1(1 \%)$ & $0(0 \%)$ & - \\
\hline \multicolumn{5}{|l|}{ Single ventricle morphology } \\
\hline Right & $99(92 \%)$ & $65(90 \%)$ & $34(97 \%)$ & - \\
\hline Left & $6(6 \%)$ & $5(7 \%)$ & $1(3 \%)$ & - \\
\hline Ambiguous & $2(2 \%)$ & $2(3 \%)$ & $0(0 \%)$ & - \\
\hline Intact/restrictive interatrial septum & $10(9 \%)$ & $7(10 \%)$ & $3(9 \%)$ & - \\
\hline Diminutive ascending aorta $(<2 \mathrm{~mm})$ & $42(39 \%)$ & $28(39 \%)$ & $14(40 \%)$ & - \\
\hline Size $(\mathrm{mm})$ of ascending aorta (mean) & $3.7 \pm 2.1$ & $3.5 \pm 1.9$ & $4.0 \pm 2.3$ & .36 \\
\hline \multicolumn{5}{|l|}{ Intraoperative } \\
\hline \multicolumn{5}{|l|}{ Technique } \\
\hline Homograft cuff & $33(30 \%)$ & $15(20 \%)$ & $18(51 \%)$ & - \\
\hline $\begin{array}{l}\text { Circumferential tube homograft with end-to-side ascending } \\
\text { aortic anastomosis }\end{array}$ & $48(45 \%)$ & $32(44 \%)$ & $16(46 \%)$ & 一 \\
\hline $\begin{array}{l}\text { Circumferential tube homograft without end-to-side } \\
\text { aortic anastomosis }\end{array}$ & $27(25 \%)$ & $26(36 \%)$ & $1(3 \%)$ & - \\
\hline RV-PA conduit & $94(88 \%)$ & $63(87 \%)$ & $31(89 \%)$ & - \\
\hline Systemic-PA shunt & $13(12 \%)$ & $9(13 \%)$ & $4(11 \%)$ & - \\
\hline \multicolumn{5}{|l|}{ Postoperative } \\
\hline Postoperative ECMO & $23(21 \%)$ & $16(22 \%)$ & $7(20 \%)$ & - \\
\hline Operative mortality & $22(20.5 \%)$ & $13(18.1 \%)$ & $9(25.7 \%)$ & .45 \\
\hline Late mortality & $13(12.1 \%)$ & $7(9.7 \%)$ & $7(20.0 \%)$ & - \\
\hline Overall mortality & $36(33.6 \%)$ & $20(27.8 \%)$ & $16(45.7 \%)$ & .08 \\
\hline Interstage death $(1 \rightarrow 2)$ & $25(23.3 \%)$ & $1(1.4 \%)$ & $3(8.6 \%)$ & - \\
\hline Interstage death $(2 \rightarrow 3)$ & $7(6.5 \%)$ & $5(6.9 \%)$ & $1(2.9 \%)$ & - \\
\hline Follow-up, y (median) & $3.0(1.8-5.0)$ & $2.2(1.6-3.0)$ & $5.4(4.9-6.3)$ & $<.001$ \\
\hline \multicolumn{5}{|l|}{ Neoaortic coarctation } \\
\hline Neoaortic coarctation* & $37(37 / 85=44 \%)$ & $25(25 / 59=42 \%)$ & $12(12 / 26=46 \%)$ & .81 \\
\hline Coarctation with circumferential tube homograft & $24(24 / 57=42 \%)$ & $19(19 / 46=41 \%)$ & $5(5 / 11=45 \%)$ & 1.00 \\
\hline Coarctation with homograft cuff & $13(13 / 28=46 \%)$ & $6(6 / 13=46 \%)$ & $7(7 / 15=47 \%)$ & 1.00 \\
\hline Narrowing distal to LSA & $33(33 / 37=89 \%)$ & $22(22 / 25=88 \%)$ & $11(11 / 12=92 \%)$ & 1.00 \\
\hline Narrowing in ascending aorta & $7(7 / 37=19 \%)$ & $5(5 / 25=20 \%)$ & $2(2 / 12=16 \%)$ & 1.00 \\
\hline Narrowing distal to LSA and in ascending aorta (at separate times) & $3(3 / 37=8 \%)$ & $2(2 / 25=8 \%)$ & $1(1 / 12=8 \%)$ & 1.00 \\
\hline
\end{tabular}

Continuous data are presented as mean \pm standard deviation, and categorical data presented as number (percentages). HLHS, Hypoplastic left heart syndrome; DORV, doubleoutlet right ventricle; $A V C$, atrioventricular canal; $D I L V$, double-inlet left ventricle; $D-T G A$, dextrotransposition of the great arteries; $R V$, right ventricle; $P A$, pulmonary artery; $E C M O$, extracorporeal membrane oxygenation; $L S A$, left subclavian artery. $*$ Denominator $=$ number of survivors.

and 45 unplanned cardiac catheterizations. Results of the dimensional analysis are detailed in Table 4.

Group A versus group B. The size of the neoaorta was similar in both groups if "tube grafts" were used. Use of cuff grafts resulted in larger neoaortic Z-scores in group B at pre-stage 2 cardiac catheterization (group A, $2.62 \pm 1.87$ vs group $\mathrm{B}, 4.32 \pm 2.07 ; P=.043)$. At prestage 3 cardiac catheterization, the difference still existed although was not significant (group A, $2.77 \pm 2.83$ vs group B, $4.57 \pm 1.33 ; P=.106$ [Table 4]). 
TABLE 2. Comparison of neoaortic coarctation by type of repair

\begin{tabular}{lccc}
\hline & Homograft tube & Homograft cuff & $\boldsymbol{P}$ value \\
\hline Overall & $24(42 \%)$ & $13(46 \%)$ & .82 \\
Group A & $19(41 \%)$ & $6(46 \%)$ & .76 \\
Group B & $5(45 \%)$ & $7(47 \%)$ & 1.00 \\
\hline
\end{tabular}

Interval change. With time, a progressive increase in the diameter of the ascending aorta as measured by absolute neoaortic diameter (Figure 3, $A$ and $B$ ) was seen in both groups with both technical modifications (tube grafts pre-stage 2 vs pre-stage 3: group A [10.61 $\mathrm{mm} \pm 1.93$ vs 13.74 $\mathrm{mm} \pm 3.16 ; P<.001]$ and group B $[13.93 \mathrm{~mm} \pm 6.71 \mathrm{vs}$ $17.38 \mathrm{~mm} \pm 5.92 ; P=.049$ ] [Figure 3, A]; cuff repair prestage 2 to pre-stage 3: group A [13.98 $\mathrm{mm} \pm 2.13$ vs 19.09 $\mathrm{mm} \pm 4.18 ; P=.002]$ and group B $[16.06 \mathrm{~mm} \pm 3.05$ vs $19.73 \mathrm{~mm} \pm 2.93 ; P<.001$ ] [Figure 3, $B$ ]).

There was no change in the neoaortic Z-scores with time in either group with either technical modification (tube grafts pre-stage 2 vs pre-stage 3: group A $(-0.38 \pm 1.89$ vs $0.00 \pm 2.08 ; P=.42)$ and group $\mathrm{B}(1.76 \pm 4.60 \mathrm{vs}$ $2.27 \pm 4.13 ; P=.88$ ) (Figure 3, $C$ ); cuff repair pre-stage 2 to pre-stage 3 : group A $(2.62 \pm 1.87$ vs $2.77 \pm 2.83$; $P=.38)$ and group B $(4.32 \pm 2.07$ vs $4.57 \pm 1.33$; $P=.16$ ) (Figure 3, $D$ ). The neoaortic Z-scores were generous with the use of homograft cuffs. When homograft tubes were used the neoaorta was closer to normal size.

Cuffs versus tubes. Abnormal dilation of the neoaorta ( $\mathrm{Z}$ score $>2$ ) was seen in both groups with the "cuff modification." Significantly higher neoaortic diameters and Z-scores were seen for the "cuff technique" compared with the "tube grafts" at both pre-stage 2 and pre-stage 3 for group A patients (pre-stage 2 diameter group A: cuff $13.98 \pm 2.13$ vs tube $10.61 \pm 1.93 ; P<.001$; pre-stage $2 \mathrm{Z}$ scores group A: cuff $2.62 \pm 1.87$ vs tube $-0.38 \pm 1.89 ; P<.001$; prestage 3 diameter: cuff $19.09 \pm 4.18$; tube $13.74 \pm 3.16$;

TABLE 3. Predictors of mortality by multivariable Cox proportional hazards regression

\begin{tabular}{lccc}
\hline \multicolumn{1}{c}{ Variable } & \multicolumn{3}{c}{ Hazard } \\
\hline Age at stage 1, d & .53 & - & - \\
Weight at stage 1 $(<2.5 \mathrm{~kg})$ & $.01^{*}$ & 3.7 & $1.7-7.8$ \\
Diagnosis (HLHS vs variant) & .15 & - & - \\
Morphology (LV vs RV) & .68 & - & - \\
Shunt (BT vs Sano) & .08 & - & - \\
Repair type (cuff, tube, DB) & .70 & - & - \\
ECMO after stage 1 & $<.001^{*}$ & 13.8 & $5.9-31.9$ \\
Ascending aorta diameter $<2 \mathrm{~mm}$ & .25 & - & - \\
Era of operation $(2004-2011)$ & .86 & - & - \\
Biomaterial (others vs FV) & $.01 *$ & 3.0 & $1.4-6.4$ \\
\hline
\end{tabular}

$C I$, Confidence interval; $H L H S$, hypoplastic left heart syndrome; $L V$, left ventricle; $R V$, right ventricle; $B T$, Blalock-Taussig; $D B$, double-barrel; $E C M O$, extracorporeal membrane oxygenation; $F V$, femoral vein. *Statistically significant predictor.

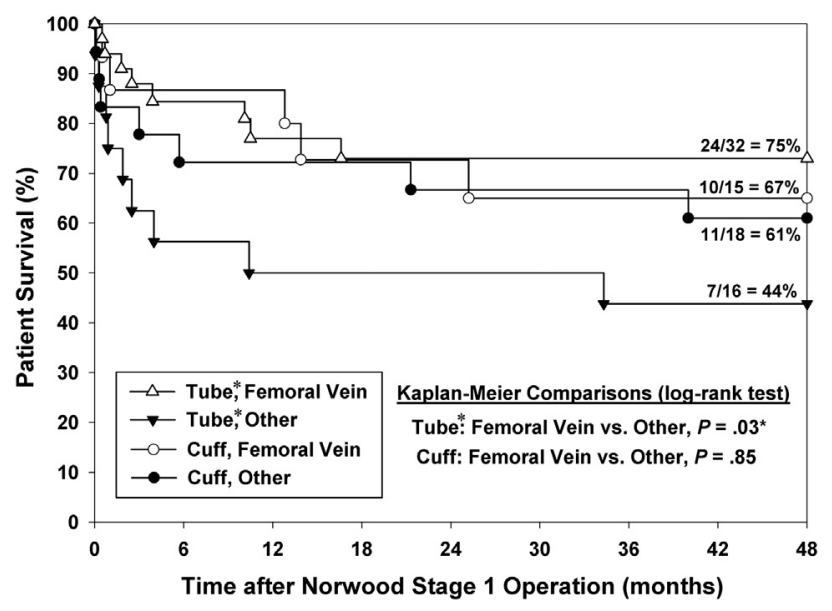

FIGURE 2. Kaplan-Meier curve representing survival after Norwood stage 1 operation. *Significant difference with use of circumferential femoral vein homograft with end-to-side anastomosis of the ascending aorta.

$P<.001$; pre-stage $3 \mathrm{Z}$ score: cuff $2.77 \pm 2.83$; tube $0.00 \pm 2.08 ; P=.008)$. A similar trend was noted in group $\mathrm{B}$ but was not significant.

Neoaortic coarctation. Of the 85 survivors, 37 (44\%) had neoaortic coarctation as defined by need for balloon angioplasty and/or surgical arch augmentation. Similar neoaortic coarctation rates were seen in both groups (A: 25/59 [42\%]; B: $12 / 26[46 \%] ; P=.81$ ) (Table 1). There was no difference in coarctation rate by type of repair (tube: 24/57 [42\%]; cuff: $13 / 28$ [46\%]; $P=.82$ ) (Table 2). The narrowing was distal to the left subclavian artery in $89 \%$ (33/37; group A, 22; group B, 11) of patients with recoarctation. Ascending neoaortic narrowing was seen in 7 patients (group A, 5; group B, 2), all of whom had a circumferential tube homograft repair. Three patients had narrowing of the neoaorta at both locations, albeit at separate points in time.

Balloon angioplasty alone was required in 19 patients in group A and 7 in group B. Poor response to balloon angioplasty led to surgical arch augmentation in 2 patients in group A and 1 patient in group B. Location and nature of the narrowing prompted direct operative aortic intervention in 3 patients in group A and 4 in group B. Of the 5 patients in group A with ascending neoaortic narrowing, 3 had surgical aortic augmentation, 1 had balloon angioplasty, and 1 required surgical aortic augmentation after angioplasty; both the patients in group B with ascending neoaortic narrowing underwent surgical aortic augmentation. Of all patients with ascending neoaortic narrowing, 2 patients in group A and 1 in group B also had additional neoaortic coarctation distal to the left subclavian artery successfully treated with balloon angioplasty at the pre-stage 2 cardiac catheterization. Multivariable analysis confirmed that diagnosis of HLHS was the only significant predictor of coarctation of the neoaorta $(P=.008)$. 
TABLE 4. Predictors of mortality by ascending aorta size and $\mathrm{Z}$ scores for patients who underwent the Norwood procedure with femoral vein and other homografts stratified by repair type

\begin{tabular}{|c|c|c|c|c|c|}
\hline \multirow[b]{2}{*}{ Pre-Glenn cath } & \multicolumn{2}{|c|}{ Femoral vein (group A) } & \multicolumn{2}{|c|}{ Other homografts (group B) } & \multirow[b]{2}{*}{$P$ value } \\
\hline & Mean \pm SD & $\mathbf{n}$ & Mean \pm SD & $\mathbf{n}$ & \\
\hline \multicolumn{6}{|l|}{ Tube or double-barrel } \\
\hline Neoaorta, mm & $10.61 \pm 1.93 \dagger$ & 39 & $13.93 \pm 6.71$ & 7 & .240 \\
\hline Z-score & $-0.38 \pm 1.89 \dagger$ & 39 & $1.76 \pm 4.60$ & 7 & .268 \\
\hline \multicolumn{6}{|l|}{ Cuff repair } \\
\hline Neoaorta, mm & $13.98 \pm 2.13$ & 11 & $16.06 \pm 3.05$ & 14 & .067 \\
\hline Z-score & $2.62 \pm 1.87$ & 11 & $4.32 \pm 2.07$ & 14 & $.043^{*}$ \\
\hline Pre-Fontan cath & Mean \pm SD & $\mathbf{n}$ & Mean \pm SD & $\mathbf{n}$ & $P$ value \\
\hline \multicolumn{6}{|l|}{ Tube or double-barrel } \\
\hline Neoaorta, mm & $13.74 \pm 3.16 \dagger$ & 19 & $17.38 \pm 5.92$ & 6 & .200 \\
\hline Z-score & $0.00 \pm 2.08 \dagger$ & 18 & $2.27 \pm 4.13$ & 6 & .246 \\
\hline \multicolumn{6}{|l|}{ Cuff repair } \\
\hline Neoaorta, mm & $19.09 \pm 4.18$ & 9 & $19.73 \pm 2.93$ & 12 & .683 \\
\hline Z-score & $2.77 \pm 2.83$ & 9 & $4.57 \pm 1.33$ & 12 & .106 \\
\hline
\end{tabular}
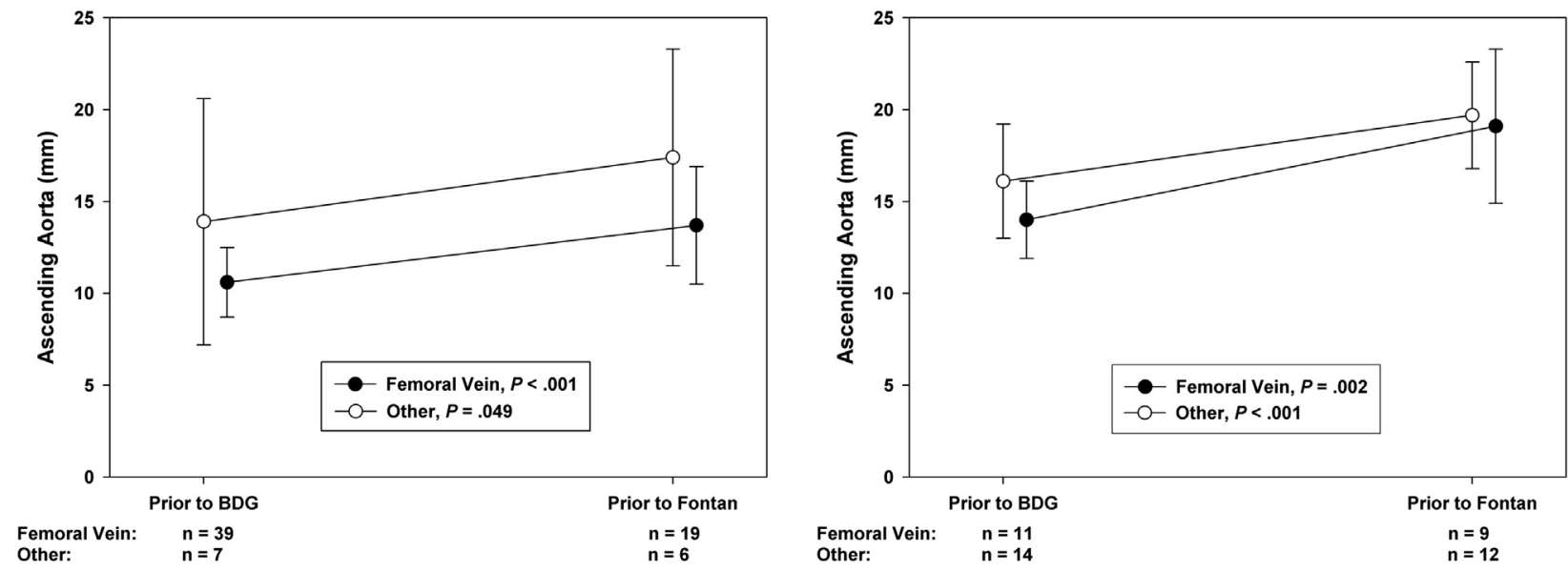

A

B
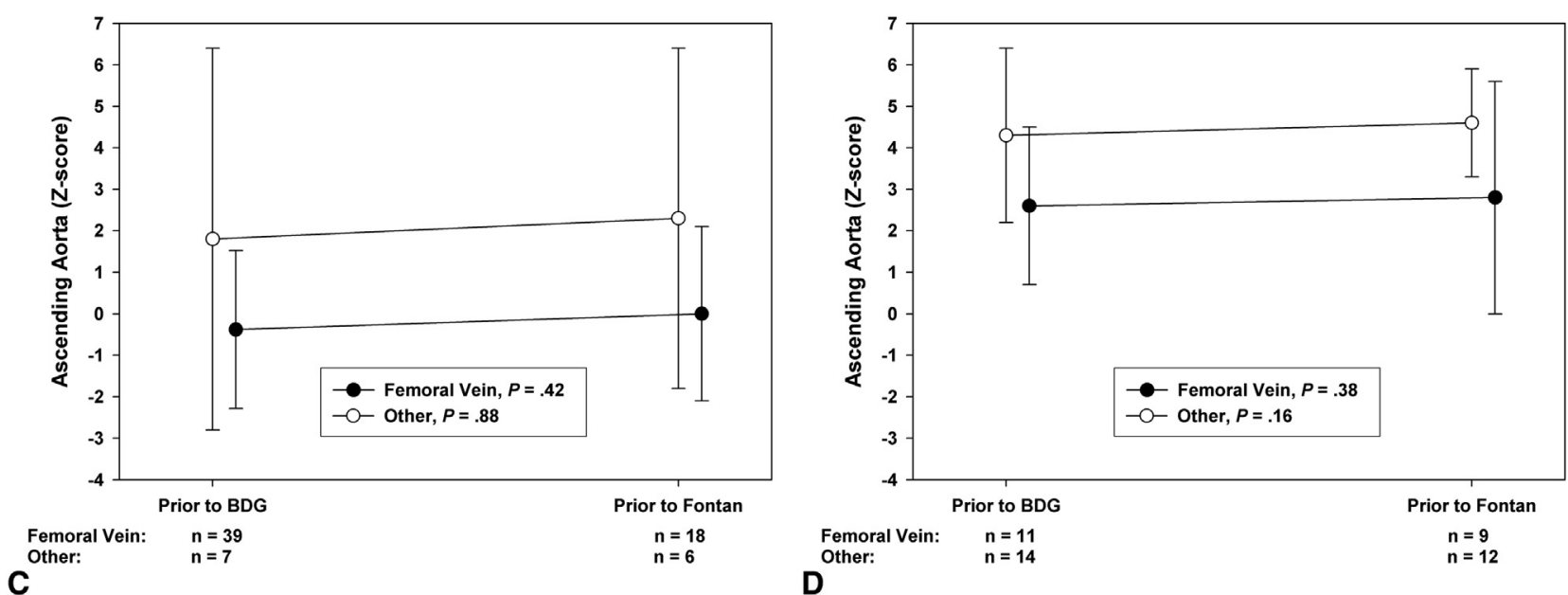

FIGURE 3. Neoaortic size with follow-up. Absolute neoaortic diameter in millimeters by type of repair. A, Circumferential tube homograft with or without end-to-side ascending aortic anastomosis: Femoral vein homografts (group A) vs others (group B). B, Homograft cuff: Femoral vein homografts (group A) vs others (group B). Neoaortic Z scores. C, Circumferential tube homograft with or without end-to-side ascending aortic anastomosis: Femoral vein homografts (group A) vs others (group B). D, Homograft cuff: Femoral vein homografts (group A) vs others (group B). BDG, Bidirectional Glenn. 


\section{DISCUSSION}

The use of femoral vein homograft offers several advantages for neoaortic reconstruction in the Norwood stage 1 operation. Inasmuch as cryopreserved femoral vein homografts are harvested from adult donors, they are widely available compared with pediatric aortic or pulmonary homografts. In addition to its lower cost, femoral vein homograft is supplied as 20- to $30-\mathrm{cm}$ long segments tapering from 15 to 16 to 10 to $11 \mathrm{~mm}$ in diameter, allowing intraoperative selection of optimum-sized segment. The femoral vein tissue is thin walled, thus being particularly suitable for end-to-side reimplantation of a particularly diminutive ascending aorta, thus greatly simplifying this technically challenging operation. Despite its thinness, the tissue is strong and hemostatic. ${ }^{4}$ The femoral vein also offers the versatility of being used as a "homograft cuff" in a standard stage 1 Norwood operation when the ascending aorta is not diminutive, or for use as a "tube graft without end-to-side anastomosis of the ascending aorta (double-barrel technique)" for HLHS variants with a nearly normal sized ascending aorta.

In this study the use of femoral vein homograft was a negative predictor of mortality, with significant survival benefit in the higher risk patients with diminutive ascending aorta $(<2 \mathrm{~mm})$ when used as a tube graft with end-to-side ascending aortic reimplantation. Our findings of weight less than $2.5 \mathrm{~kg}$ at stage 1 and need for ECMO in the immediate postoperative period being predictive of mortality are consistent with previous reports. ${ }^{9,10}$ The characteristics of the groups were similar with regard to prematurity, weight less than $2.5 \mathrm{~kg}$, presence of intact/restrictive atrial septum, prevalence of a diminutive ascending aorta, and need for postoperative ECMO. No correlation between date of stage 1 operation (era effect) and mortality was found across the entire study period.

There was no difference in the rate of neoaortic coarctation evident between biomaterials used or between types of repair. In an attempt to focus on late aortic arch obstruction, we excluded operative mortalities from the neoaortic coarctation analysis. Additionally, strict definition of recoarctation and low threshold for intervention may overestimate the overall neocoarctation rates in this study. Nonetheless, the similar rates of neoaortic recoarctation between groups suggest that femoral vein homograft imparts no greater risk of recoarctation than standard biomaterials.

Although there are growing concerns with severely dilated neoaortas after the stage 1 Norwood operation with the standard cuff technique, the use of tube grafts has a risk of subsequent neoaortic stenosis owing to their lack of growth potential. It is reassuring in this study that the use of homograft tubes did not lead to higher rates of neoaortic stenosis than did the cuff grafts. On the other hand, an interesting progressive increase in the neoaortic size was seen commensurate with somatic growth. In fact, the neoaortic Z-scores were maintained in the modestly dilated range. This could be due to dilation of the homograft with time, especially with femoral vein homografts, supplemented by the growth potential of the incorporated ascending aorta. Technical modifications such as making the end-to-side aortic reimplantation as long as possible limits the rim of nongrowing circumference to a few millimeters at the proximal and distal homograft tube anastomotic sites only, with the majority of the homograft circumference still left with growth potential.

This report has the limitation of being a single-center, retrospective study with a limited number of patients and short- to intermediate-term follow-up. Greater longitudinal follow-up is needed to determine the long-term outcomes of these patients. However, this is the only report of an attractive alternative biomaterial and technique for neoaortic reconstruction for the stage 1 Norwood operation.

\section{CONCLUSIONS}

Survivals are improved with the use of the femoral vein homograft for neoaortic reconstruction for the Norwood stage 1 operation, especially when used as a homograft tube with end-to-side aortic reimplantation. Femoral vein homografts have recoarctation rates similar to those of standard biomaterials. With appropriate technical modifications, homograft tube grafts and homograft cuffs have similar recoarctation rates. Progressive growth/dilation of the neoaorta in proportion to somatic growth is seen with femoral vein tube grafts. The cryopreserved femoral vein homograft is an excellent alternative biomaterial for neoaortic reconstruction in the Norwood stage 1 operation.

\section{References}

1. Morell VO, Wearden PA. Experience with bovine pericardium for the reconstruction of the aortic arch in patients undergoing a Norwood procedure. Ann Thorac Surg. 2007;84:1312-5.

2. Gargiulo G, Pace Napoleone C, Solinas M, Frascaroli G, Pierangeli A. A new patch for the Norwood procedure. Ann Thorac Surg. 1999;68:1873-4.

3. Healy DG, Nolke L, Wood AE. Bovine jugular vein as a shaped alternative patch material for aortic augmentation in the Norwood procedure. J Thorac Cardiovasc Surg. 2007;133:567-8.

4. Sinha P, Moulick A, Jonas RA. Femoral vein homograft for neoaortic reconstruction in Norwood stage 1 operation. Ann Thorac Surg. 2009;87:1309-10.

5. Jonas RA. Comprehensive surgical management of congenital heart disease. 1st ed. London: Hodder Arnold; 2004.

6. Warren AE, Boyd ML, O'Connell C, Dodds L. Dilatation of the ascending aorta in paediatric patients with bicuspid aortic valve: frequency, rate of progression and risk factors. Heart. 2006;92:1496-500.

7. Lemler MS, Zellers TM, Harris KA, Ramaciotti C. Coarctation index: identification of recurrent coarctation in infants with hypoplastic left heart syndrome after the Norwood procedure. Am J Cardiol. 2000;86:697-9. A9.

8. Bautista-Hernandez V, Marx GR, Gauvreau K, Pigula FA, Bacha EA, Mayer JE Jr, et al. Coarctectomy reduces neoaortic arch obstruction in hypoplastic left heart syndrome. J Thorac Cardiovasc Surg. 2007;133:1540-6.

9. Mahle WT, Spray TL, Wernovsky G, Gaynor JW, Clark BJ 3rd. Survival after reconstructive surgery for hypoplastic left heart syndrome: a 15-year experience from a single institution. Circulation. 2000;102(19 Suppl 3):III136-41.

10. Ravishankar C, Dominguez TE, Kreutzer J, Wernovsky G, Marino BS, Godinez R, et al. Extracorporeal membrane oxygenation after stage I reconstruction for hypoplastic left heart syndrome. Pediatr Crit Care Med. 2006;7:319-23. 